\title{
Оценка хранения лука репчатого в однолетней культуре в Нечерноземной зоне
}

\author{
Assessment of storage of onion grown as annual crop in the Non-Chernozem zone
}

Давлетбаева О.Р., Ибрагимбеков М.Г., Ховрин А.Н.

\section{Аннотация}

Представлена оценка сохранности сортов, гибридов и новых гибридных комбинаций лука репчатого выращенного в однолетней культуре в условиях Московской области. Лежкость селекционных образцов лука оценивали в период зимнего хранения, учитывали убыль массы, число усохших, пораженных и проросших луковиц. По количеству сохранившихся луковиц и динамике этих показателей оценивали сохранность образцов. Сохранность лука репчатого зависит еще от пригодности данного сорта или гибрида к длительному хранению и его вызревания. Полное вызревание лука характеризуется наличием сухих кроющих чешуй, усыханием листьев и шейки, высоким содержанием сахарозы и моносахаров. Такой лук хранится дольше и меньше поражается болезнями. Один из важных способов сокращения потерь лука репчатого при хранении является соблюдение низкотемпературного режима и соответствующей влажности воздуха. Для лучшей сохранности лука поддерживали температуру в хранилище около 1-2 ${ }^{\circ} \mathrm{C}$, относительной влажностью воздуха в пределах $75-80 \%$. Для этого лук закладывали в хранилище с оборудованными холодильными установками, автоматически регулирующими температуру, влажность и циркуляцию воздуха. Большинство образцов имели сохранность от $28,3 \%$ до $71,1 \%$, что составило более половины - 69,2\% изучаемых образцов. Самый низкий показатель сохранности имел образец 652/17 $\mathrm{F}_{1}$ (Шет×AN $158 \mathrm{I}_{3}$ ) и составил $28,3 \%$, также данный образец имел $42,3 \%$ проросших луковиц. Лучшую сохранность 95\% и 94,6\% показали образцы зарубежной селекции $\mathrm{F}_{1}$ Сантеро и $\mathrm{F}_{1}$ Премито (стандарт), при содержании сухого вещества $10,9 \%$ и $10,8 \%$ соответственно. Также хорошую сохранность среди гибридных комбинаций показал образец 652/2 $\mathrm{F}_{1}$ (Шет $\times$ Поло $\mathrm{I}_{3}$ ) - 85\% с содержанием сухого вещества $10,2 \%$, уступив отечественному сорту Форвард (стандарт) на $1,8 \%$.

Ключевые слова: лук репчатый, хранение, сохраняемость, сорт, гибрид.

Для цитирования: Давлетбаева О.Р., Ибрагимбеков М.Г., Ховрин А.Н. Оценка хранения лука репчатого в однолетней культуре в Нечерноземной зоне // Картофель и овощи. 2020.№5. С. 1719. https://doi.org//10.25630/PAV.2020.57.81.003
Davletbaeva O.R., Ibragimbekov M.G., Khovrin A.N.

\section{Abstract}

An assessment of the safety of cultivars, hybrids and new hybrid combinations of onion grown in an annual culture in the Moscow region is presented. The yield of selected onion samples was evaluated during winter storage, taking into account the loss of weight, the number of dried, affected and sprouted bulbs. The number of preserved bulbs and the dynamics of these indicators were used to assess the safety of samples. The safety of onions depends on the suitability of this variety or hybrid for long-term storage and its aging. Full maturation of onions is characterized by the presence of dry covering scales, drying of leaves and neck, high content of sucrose and monosaccharides. This onion is stored longer and less affected by diseases. One of the important ways to reduce the loss of onions during storage is to observe a low-temperature regime and appropriate humidity. For better preservation of onions, the storage temperature was maintained at about $1-2{ }^{\circ} \mathrm{C}$, with a relative humidity of $75-80 \%$. To do this, the onion was placed in a storage with equipped refrigeration units that automatically regulate temperature, humidity and air circulation. The majority of samples had a safety of $28.3 \%$ to $71.1 \%$, which was more than half- $69.2 \%$ of the studied samples. The lowest preservation rate was for the $652 / 17 \mathrm{~F}_{1}$ sample (Shet $\times A N 158 \mathrm{I}_{3}$ ) and was $28.3 \%$, and this sample also had $42.3 \%$ sprouted bulbs. The best preservation of $95 \%$ and $94.6 \%$ were shown by samples of foreign selection $F_{1}$ Santero and $F_{1}$ Premito (standard), with a dry matter content of $10.9 \%$ and $10.8 \%$, respectively. Also, the $652 / 2 F_{1}$ (Shet $\times$ Polo $\mathrm{I}_{3}$ ) sample showed good preservation among hybrid combinations $-85 \%$ with a dry matter content of $10.2 \%$, losing to the domestic Forvard (standard) cultivar by $1.8 \%$.

Key words: onions, storage, shelf life, cultivar, hybrid.

For citing: Davletbaeva O.R., Ibragimbekov M.G., Khovrin A.N. Assessment of storage of onion grown as annual crop in the NonChernozem zone. Potato and vegetables. 2020. No5. Pp. 17-19. https:// doi.org//10.25630/PAV.2020.57.81.003 (In Russ.). реди луковых культур в нашей стране наибольшее распространение получил лук репчатый. Он занимает более 95\% площади под всеми видами лука. По занимаемым площадям лук находится на третьем месте в мире среди овощных культур, уступая только томату и арбузу. В России лук репчатый выращивают на площади от 88 до 96 тыс. га и занимает третье место, уступая капусте и томату $[1,2]$.

Увеличение объемов производства лука репчатого происходит не только за счет увеличения площадей, занимаемых культурой, но и за счет повышения урожайности. Это достигается внедрением в производство новых высокопродуктивных сортов и гибридов, повышением общей культуры земледелия и уровня технологии возделывания. Также актуальный вопрос сегодня - лежкоспособность лука репчатого, т.к. население страны необходимо обеспечивать луком в течение всего года [3].

Заложенный на хранение лук не должен потерять своих товарных качеств в течение максималь- но длительного периода времени. Способность сортов и гибридов лука к хранению связана с их происхождением, длительностью и глубиной периода покоя, биохимическими особенностями. В процессе хранения происходит внутреннее развитие луковиц и медленными темпами осуществляются процессы жизнедеятельности, в частности дыхание, на что расходуются пластические вещества. Поэтому естественная убыль неизбежна. Она составляет для лука репчатого 6-7\%. Чтобы снизить общие потери про- 


\section{Результаты оценки сохранности лука репчатого после семи месяцев хранения, среднее за 2018-2019 годы}

\begin{tabular}{|c|c|c|c|c|c|c|}
\hline \multirow{2}{*}{ Образец } & \multicolumn{2}{|c|}{$\begin{array}{c}\text { Масса продукции заложенного } \\
\text { образца, кг }\end{array}$} & \multirow{2}{*}{$\begin{array}{c}\text { Содержание } \\
\text { сухого } \\
\text { вещества,\% }\end{array}$} & \multirow{2}{*}{ Сохранность,\% } & \multirow{2}{*}{$\begin{array}{l}\text { Проросшие } \\
\text { луковицы,\% }\end{array}$} & \multirow{2}{*}{$\begin{array}{l}\text { Пораженные } \\
\text { луковицы,\% }\end{array}$} \\
\hline & до хранения & после хранения & & & & \\
\hline $\mathrm{F}_{1}$ Поиск 012 & 28,4 & 20,2 & 9,8 & 71,1 & 14,4 & 14,4 \\
\hline$F_{1}$ Есаул & 29,4 & 17,2 & 8,7 & 58,5 & 35,3 & 6,2 \\
\hline $\mathrm{F}_{1}$ Сантеро & 16,1 & 15,3 & 10,9 & 95,0 & 1,0 & 4,0 \\
\hline $\mathrm{F}_{1} 652 / 2\left(\right.$ Шет $\times$ Поло I $\left.{ }_{3}\right)$ & 10,7 & 9,1 & 10,2 & 85,0 & 7,6 & 7,3 \\
\hline $\mathrm{F}_{1} 652 / 4$ (Шет × Марина I ${ }_{3}$ ) & 17,8 & 11,6 & 11,0 & 65,2 & 30,7 & 4,2 \\
\hline $\mathrm{F}_{1} 652 / 6$ (Шет × AN 158) & 31,8 & 19,6 & 11,1 & 61,6 & 30,7 & 7,7 \\
\hline $\mathrm{F}_{1} 652 / 19$ (Шет × Банко I $)$ & 9,1 & 6,3 & 10,4 & 69,2 & 24,0 & 6,8 \\
\hline $\mathrm{F}_{1} 652 / 9\left(\right.$ Шет $\times$ Бонус $\left.\mathrm{I}_{2}\right)$ & 33,0 & 16,4 & 9,2 & 49,7 & 34,7 & 15,6 \\
\hline $\mathrm{F}_{1} 652 / 14$ (Шет $\times$ Densiti $\mathrm{I}_{3}$ ) & 33,4 & 18,8 & 10,0 & 56,3 & 26,2 & 17,5 \\
\hline $\mathrm{F}_{1} 652 / 15$ (Шет ×Ливингстон $\mathrm{I}_{3}$ ) & 33,3 & 14,9 & 9,5 & 44,7 & 43,7 & 11,6 \\
\hline $\mathrm{F}_{1} 652 / 17\left(\right.$ Шет $\left.\times \mathrm{AN} 158 \mathrm{I}_{3}\right)$ & 39,6 & 11,2 & 9,2 & 28,3 & 42,3 & 29,4 \\
\hline Форвард (стандарт) & 23,4 & 20,3 & 10,8 & 86,8 & 2,6 & 10,6 \\
\hline$F_{1}$ Премито (стандарт) & 30,1 & 28,9 & 10,8 & 94,6 & 1,1 & 4,3 \\
\hline $\mathrm{HCP}_{05}$ & & & 0,5 & 12,1 & & \\
\hline
\end{tabular}

дукции, создают оптимальные условия хранения. Сохранность лука репчатого зависит еще от пригодности данного сорта или гибрида к длительному хранению и его вызревания. Полное вызревание лука характеризуется наличием сухих кроющих чешуй, усыханием листьев и шейки, высоким содержанием сахарозы и моносахаров. Такой лук хранится дольше и меньше поражается болезнями [4].

Лежкость селекционных образцов лука оценивают в период зимнего хранения. Учитывают убыль массы, число усохших, пораженных и проросших луковиц, а также изменение в зачатковости. По количеству сохранившихся луковиц и динамике этих показателей судят о ценности образца.
Цель исследования: изучение сохранности селекционных образцов лука репчатого.

Условия, материалы и методы исследований

Исследования

проводили в 2018-2019 годах на луке, выращенном в однолетней культуре в условиях Быковского расширения Москворецкой поймы Московской области. Рельеф участка равнинный. Толщина перегнойного горизонта до 80 см. Пахотный слой содержит гумуса 3,5\%, подвижного фосфора - 20,5 мг/100 г почвы, калия 14,2 мг/100 г почвы, $\mathrm{pH}$ солевой вытяжки 6,0.

К уборке лука репчатого приступили при полегании 70\% пера, при полностью сформированной луковице. Убирали вручную в теплую, сухую погоду. Лук оставляли в поле в валках для сушки и дозревания (рис. 1, 2), через 7-14 дней перемещали его под навес для дальнейшей досушки, т.к. хорошо высушенный лук репчатый обеспечивает барьер для потери воды при хранении и исключении попадания инфекции, тем самым сохраняя товарные качества [5]. Далее проводили послеуборочную обработку, включающую в себя обрезку листьев лука и корней, готовую продукцию помещали в ящики и закладывали на хранение (рис. 3). Один из важных способов сокращения потерь лука репчатого при хранении - соблюдение низкотемпературного режима и соответствующей влажности воздуха. Для этого лук закладывали в хранилище с оборудованными холо-

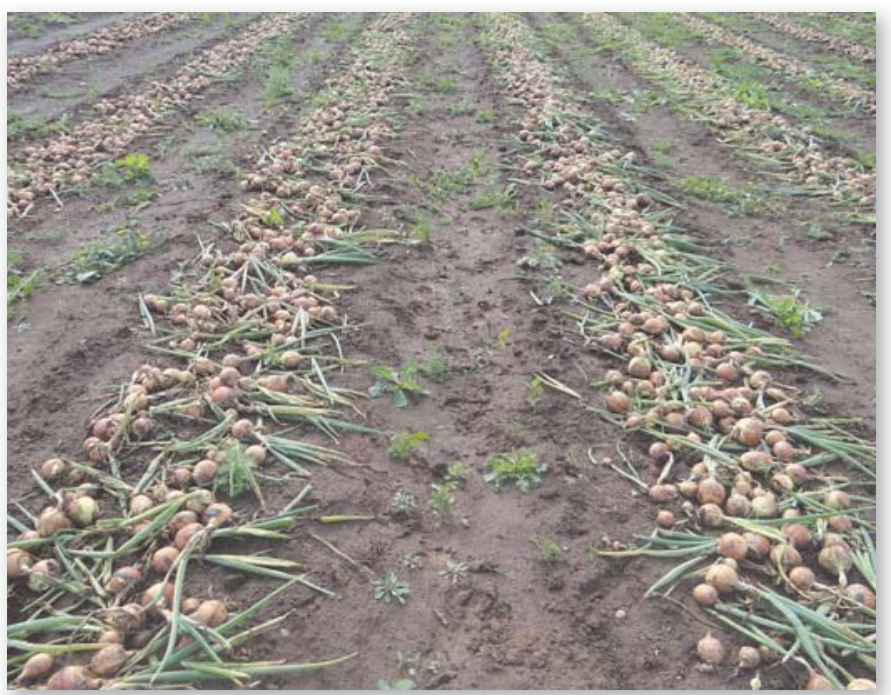

Рис. 1. Лук репчатый в валках на опытном участке

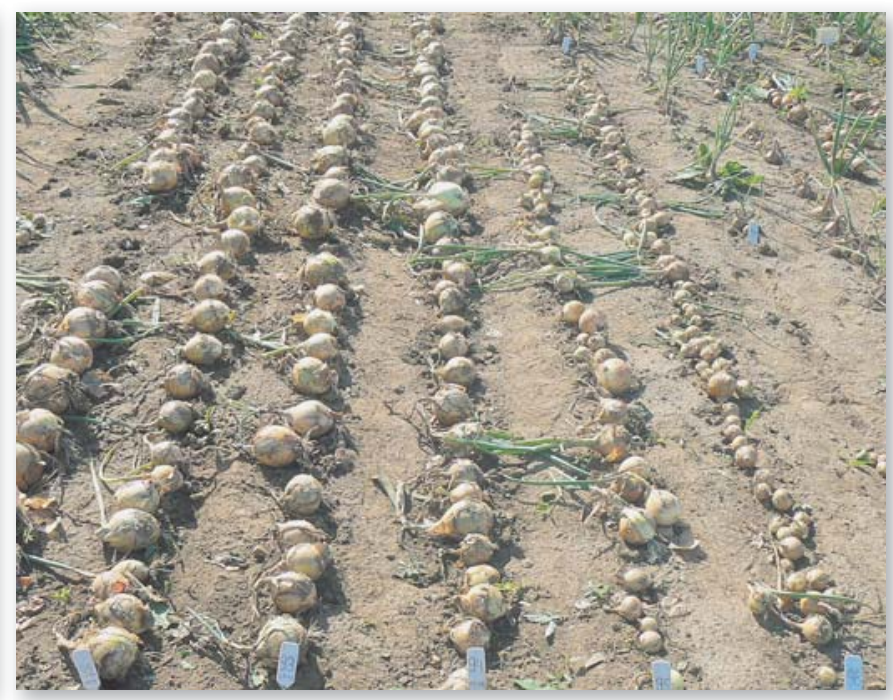

Рис.2. Образцы лука репчатого на опытном участке 


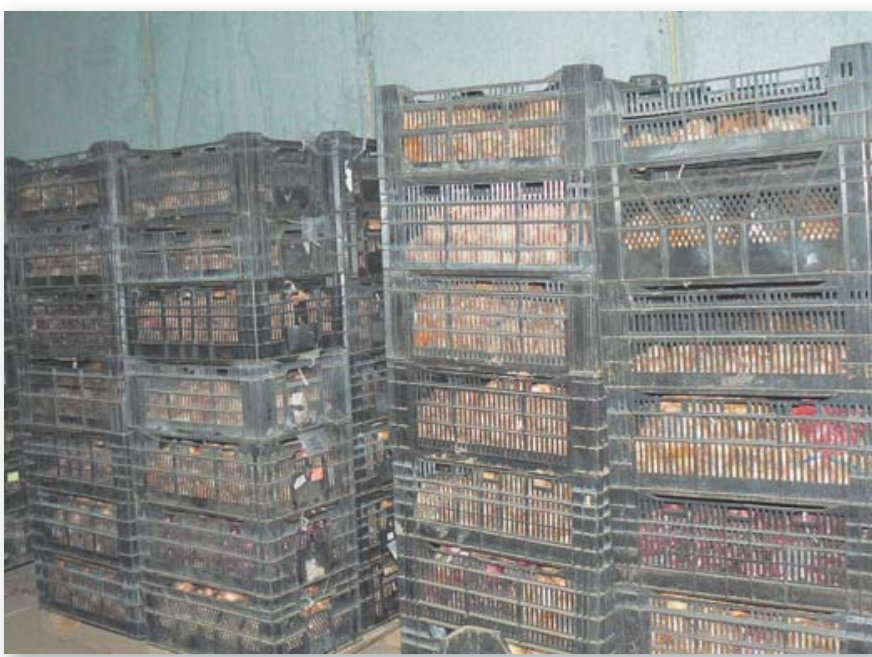

Рис. 3. Селекционные образцы лука репчатого, заложенного на хранение

дильными установками, автоматически регулирующими температуру, влажность и циркуляцию воздуха. Сортировку лука при хранении проводили вручную. С интервалом один раз в месяц лук просматривали и вели учет, все больные и проросшие луковицы удаляли, если обнаруживали очаги заболевания. Лежкость селекционных образцов лука оценивали в период зимнего хранения, учитывали убыль мас- сы, число усохших, пораженных и проросших луковиц. По количеству сохранившихся луковиц и динамике этих показателей оценивали сохранность образцов. Сохранность лука репчатого зависит еще от пригодности данного сорта или гибрида к длительному хранению и его вызревания. Полное вызревание лука характеризуется наличием сухих кроющих чешуй, усыханием листьев и шейки, высоким содержанием сахарозы и моносахаров. Для лучшей сохранности лука поддерживали температуру в хранилище около $1-2{ }^{\circ} \mathrm{C}$, относительной влажностью воздуха в пределах 75-80\%.

\section{Результаты исследований}

Изучаемые образцы лука репчатого существенно отличались между собой по сохраняемости (табл.).
Большинство образцов имели сохранность от $28,3 \%$ до $71,1 \%$, что составило более половины - 69,2\% изучаемых образцов. Самый низкий показатель сохранности имел образец 652/17 $F_{1}\left(\right.$ Шет $\times$ AN $\left.158 I_{3}\right)-28,3 \%$, также данный образец имел 42,3\% проросших луковиц. Лучшую сохранность 95\% и 94,6\% показали образцы иностранной селекции $\mathrm{F}_{1}$ Сантеро и $\mathrm{F}_{1}$ Премито (стандарт), при содержании сухого вещества 10,9\% и $10,8 \%$ соответственно. Также хорошую сохранность среди гибридных комбинаций показал образец 652/2 $\mathrm{F}_{1}$ (Шет х Поло $\mathrm{I}_{3}$ ) - 85\% с содержанием сухого вещества $10,2 \%$, уступив отечественному сорту Форвард (стандарт) на 1,8\%.

\section{Выводы}

По результатам исследований, лучшую сохранность показали образцы иностранной селекции $\mathrm{F}_{1}$ Сантеро и $\mathrm{F}_{1}$ Премито (стандарт) - 95\% и 94,6\%, при содержании сухого вещества 10,9\% и 10,8\% соответственно. У сорта отечественной селекции Форвард эти показатели были на уровне данных гибридов и составили: $10,8 \%$ и $86,8 \%$ соответственно.Самый низкий показатель сохранности имел образец 652/17 $\mathrm{F}_{1}$ $\left(\right.$ Шет $\times$ AN $\left.158 I_{3}\right)-28,3 \%$.

\section{Библиографический список}

1.Ибрагимбеков М.Г., Давлетбаева О.Р., Ховрин А.Н. Экологическое испытание нового полуострого сорта лука репчатого Форвард для однолетней культуры в условиях республики Марий Эл // Овощи России. 2018. №5. C. 54-56. https://doi. org/10.18619/2072-9146-2018-5-54-56

2.Ховрин А.Н., Монахос Г.Ф. Производство и селекция лука репчатого в России // Картофель и овощи. 2014. №7. С. 18.

3.Ховрин А.Н., Давлетбаева О.Р., Ибрагимбеков М.Г. Гибриды лука селекции Агрохолдинга «Поиск» в однолетней культуре // Картофель и овощи. 2019. № 9. С. 18-19.

4.Давлетбаева О.Р., Ибрагимбеков М.Г., Ховрин А.Н. Оценка коллекции лука репчатого по признакам листовой розетки и луковицы // Овощи России. 2018. № 4. С. 29-32. https://doi. org/10.18619/2072-9146-2018-4-29-32

5.Изучение и поддержание в живом виде мировой коллекции лука и чеснока (методические указания). СПб.: ВНИИР имени Н.И. Вавилова, 2005. 69 с.

\section{References}

1.Ibragimbekov M.G., Davletbaeva O.R., Khovrin A.N. Ecological testing of a new raw onion variety forward For an annual crop in the conditions of the Republic of Mari El. Vegetables of Russia. 2018. No.5. Pp. 54-56. https://doi.org/10.18619/2072-9146-2018-5-5456 (In Russ.).

2.Khovrin A.N., Monahos G.F. Production and breeding of onion in Russia. Potato and vegetables. 2014. No.7. Pp. 18 (In Russ.).

3.Khovrin A.N., Davletbaeva O.R., Ibragimbekov M.G. Hybrids of onion bred in Poisk Agro Holding in annual culture. Potato and vegetables. 2019. No. 9. Pp. 18-19 (In Russ.).

4.Davletbaeva O.R., Ibragimbekov M.G., Khovrin A.N. Evaluation of the onion collection based on the characteristics of leaf rosettes and bulbs. Vegetables of Russia. 2018. No4. Pp. 29-32. https://doi. org/10.18619/2072-9146-2018-4-29-32 (In Russ.).

5 . Study and maintenance of the world collection of onions and garlic (guideline). Saint Petersburg. VNIIR after N.I. Vavilov. 2005. 69 p. (In Russ.).

\section{Об авторах}

Давлетбаева Ольга Раисовна, канд. с.-х. наук, н.с. отдела селекции и семеноводства, ВНИИО-филиал ФГБНУ ФНЦО селекционер Агрохолдинга «Поиск». E-mail: vniioh@yandex.ru

Ибрагимбеков Магомедрасул Гасбуллаевич, канд. с.х. наук, н.с. отдела селекции и семеноводства, ВНИИОфилиал ФГБНУ ФНЦО, селекционер Агрохолдинга «Поиск». E-mail: vniioh@yandex.ru

Ховрин Александр Николаевич, канд. с.-х. наук, доцент, зав. отделом селекции и семеноводства, ВНИИО-филиал ФГБНУ ФНЦО, руководитель службы селекции и первичного семеноводства Агрохолдинга «Поиск». E-mail: vniioh@yandex.ru

\section{Author details}

Davletbaeva O.R., Cand. Sci. (Agr.), research fellow, depatment of breeding and seed growing, ARRIVG - branch of FSBSI FSVC, breeder of Poisk Agro Holding. E-mail: vniioh@yandex.ru

Ibragimbekov M.G., Cand. Sci. (Agr.), research fellow, depatment of breeding and seed growing, ARRIVG - branch of FSBSI FSVC, breeder of Poisk Agro Holding. E-mail: vniioh@yandex.ru

Khovrin A.N., Cand. Sci. (Agr.), associate professor, head of breeding and seed growing department of ARRIVG - branch of FSBS FSVC, head of department of breeding and primary seed growing, Poisk Agro Holding. E-mail: vniioh@yandex.ru 